\title{
Supramolecular Chemistry
}

\section{Recognition in water of bioactive substrates by a sulfonato $p$-tert- butylcalix[5]arene}

Giuseppe Gattuso ${ }^{\mathrm{a}}$, Anna Notti ${ }^{\mathrm{a} *}$, Sebastiano Pappalardo ${ }^{\mathrm{b}}$, Melchiorre F.

Parisi $^{\text {a* }}$ and Ilenia Pisagatti ${ }^{\mathrm{a}}$

${ }^{a}$ Dipartimento di Scienze Chimiche, Università di Messina, Viale F. Stagno d'Alcontres 31, 98166 Messina, Italy; ${ }^{b}$ Dipartimento di Scienze Chimiche, Università di Catania, Viale A. Doria 6, 95125 Catania, Italy

Corresponding author.Email: mparisi@unime.it

\section{Supplementary Material}

\footnotetext{
page Contents

S2 Experimental

S2 $\quad{ }^{1}$ H NMR Binding Experiments

S4 Figure S1. ${ }^{1} \mathrm{H}$ NMR spectra $\left(\mathrm{D}_{2} \mathrm{O}, 500 \mathrm{MHz}, 298 \mathrm{~K}\right)$ of: (a) $[\mathbf{1}]=0.22 \mathrm{mM}$; (b) $[\mathbf{1}]=[\mathrm{Pea} \cdot \mathrm{HCl}]=$ $0.20 \mathrm{mM}$; (c) $[2]=0.20 \mathrm{mM}$.

S4 Figure S2. ${ }^{1} \mathrm{H}$ NMR spectra $\left(\mathrm{D}_{2} \mathrm{O}, 500 \mathrm{MHz}, 298 \mathrm{~K}\right)$ of: (a) $[1]=0.22 \mathrm{mM}$; (b) $[1]=[\mathrm{Dopa} \cdot \mathrm{HCl}]=$ $0.20 \mathrm{mM} ;(\mathrm{c})[\mathrm{Dopa} \cdot \mathrm{HCl}]=0.20 \mathrm{mM}$.

S5 Figure S3. ${ }^{1} \mathrm{H}$ NMR spectra $\left(\mathrm{D}_{2} \mathrm{O}, 500 \mathrm{MHz}, 298 \mathrm{~K}\right)$ of: (a) $[1]=0.22 \mathrm{mM}$; (b) $[1]=[\mathrm{Sert} \cdot \mathrm{HCl}]=$ $0.20 \mathrm{mM}$; (c) $[\mathrm{Sert} \cdot \mathrm{HCl}]=0.20 \mathrm{mM}$.

S5 Figure S4. ${ }^{1} \mathrm{H}$ NMR spectra $\left(\mathrm{D}_{2} \mathrm{O}, 500 \mathrm{MHz}, 298 \mathrm{~K}\right)$ of: (a) $[1]=0.22 \mathrm{mM}$; (b) $[1]=[\mathrm{Hist} \cdot 2 \mathrm{HCl}]=$ $0.20 \mathrm{mM}$; (c) $[\mathrm{Hist} \cdot 2 \mathrm{HCl}]=0.20 \mathrm{mM}$.

S6 Figure S5. ${ }^{1} \mathrm{H}$ NMR spectra $\left(\mathrm{D}_{2} \mathrm{O}, 500 \mathrm{MHz}, 298 \mathrm{~K}\right)$ of: (a) $[\mathbf{1}]=0.22 \mathrm{mM}$; (b) $[\mathbf{1}]=[\mathrm{Nore} \cdot \mathrm{HCl}]=$ $0.20 \mathrm{mM}$; (c) [7] $=0.20 \mathrm{mM}$.

S6 Figure S6. ${ }^{1} \mathrm{H}$ NMR spectra $\left(\mathrm{D}_{2} \mathrm{O}, 500 \mathrm{MHz}, 298 \mathrm{~K}\right)$ of: (a) $[\mathbf{1}]=0.22 \mathrm{mM}$; (b) $[\mathbf{1}]=[\mathrm{Gaba} \cdot \mathrm{HCl}]=$ $0.20 \mathrm{mM}$; (c) $[\mathrm{Gaba} \cdot \mathrm{HCl}]=0.20 \mathrm{mM}$.
} 


\section{Experimental}

Sodium 5,11,17,23,29-pentakis(1,1-dimethylethyl)-31,32,33,34,35-penta(4-butoxysulfonato) calix[5] arene (1) was synthesized as reported in literature (1). Deuterium oxide 99.9\% and 2phenylethylamine hydrochloride (Pea $\cdot \mathrm{HCl}, 2), 4-(2$-aminoethyl)phenol hydrochloride (Tyrm $\cdot \mathrm{HCl}, 3)$, 4-(2-aminoethyl)-1,2-benzenediol hydrochloride (Dopa $\cdot \mathrm{HCl}, 4), 3-(2-$ aminoethyl)-5-hydroxyindole hydrochloride (Sert $\cdot \mathrm{HCl}, 5)$, 2-(4-imidazolyl)ethylamine dihydrochloride (Hist-2HCl, 6), 4-[(1R)-2-amino-1-hydroxyethyl]benzene-1,2-diol (Nore $\cdot \mathrm{HCl}, 7)$ and 4 -aminobutanoic acid $(\mathrm{Gaba} \cdot \mathrm{HCl}, 8)$ were purchased from Sigma-Aldrich.

\section{${ }^{1}$ H NMR Binding Experiments}

All spectra were recorded at $298 \mathrm{~K}$ in $\mathrm{D}_{2} \mathrm{O}$ on a Varian $500 \mathrm{MHz}$ instrument, using solvent suppression pulse sequences (either PRESAT or WET). Determination of the effective concentration of calixarene $\mathbf{1}$ present in solution in the non-aggregated form was carried out according to the quantification protocol described by Henderson (2). To this end, a $0.4 \mathrm{mM}$ solution of 1 in $\mathrm{D}_{2} \mathrm{O}$ was left to equilibrate at room temperature for $1 \mathrm{~h}$, filtered through a 0.1 $\mu \mathrm{m}$ Millipore membrane filter and then examined by ${ }^{1} \mathrm{H}$ NMR spectroscopy. Specifically, 530 $\mu \mathrm{L}$ aliquots of this solution were transferred into a $5 \mathrm{~mm}$ WILMAD NMR tube into which a stem coaxial tube (WILMAD, WGS-5BL, $50 \mathrm{~mm} \mathrm{~L} \times 2 \mathrm{~mm}$ stem o.d.), loaded with $60 \mu \mathrm{L}$ of a $20 \mathrm{mM} \mathrm{D} \mathrm{D}_{2} \mathrm{O}$ solution of maleic acid, was subsequently inserted. Accurate integration of the $\mathrm{CH}$ resonance of maleic acid $(\delta=6.28 \mathrm{ppm}) v s$ that of the ArH peaks of 1 provided, over a 48 $\mathrm{h}$ time span, a constant and reproducible value for effective receptor concentration $(0.22 \mathrm{mM})$. Routinely, $K_{\mathrm{a}}$ determinations were carried out on 1:1 host-guest solutions ( $0.20 \mathrm{mM}$ in each) obtained by mixing aliquots $(60 \mu \mathrm{L})$ of a given guest solution $\left(2.2 \mathrm{mM}\right.$, in $\left.\mathrm{D}_{2} \mathrm{O}\right)$ with $600 \mu \mathrm{L}$ of the stock solution of $1(0.22 \mathrm{mM})$. Samples of the resulting host-guest solution $(530 \mu \mathrm{L})$ were then analyzed by ${ }^{1} \mathrm{H}$ NMR in the presence of maleic acid as a quantitative internal

\footnotetext{
(1) Gattuso, G.; Notti, A.; Pappalardo, A.; Pappalardo, S.; Parisi, M.F.; Puntoriero, F. Tetrahedron Lett. 2013, $54,188-191$.

(2) Henderson, T.J. Anal. Chem. 2002, 74, 191-198.
} 
reference (see above). Effective concentrations of the free and endo-cavity complexed forms of host and guests, needed for $K_{\mathrm{a}}$ determination, were then quantitatively calculated (2) by accurate integration of convenient peaks belonging to maleic acid $(\mathrm{CH}), \mathbf{1}(\mathrm{ArH})$ and guest $\left(\alpha-\right.$ or $\left.\beta-\mathrm{CH}_{2}\right)$. 


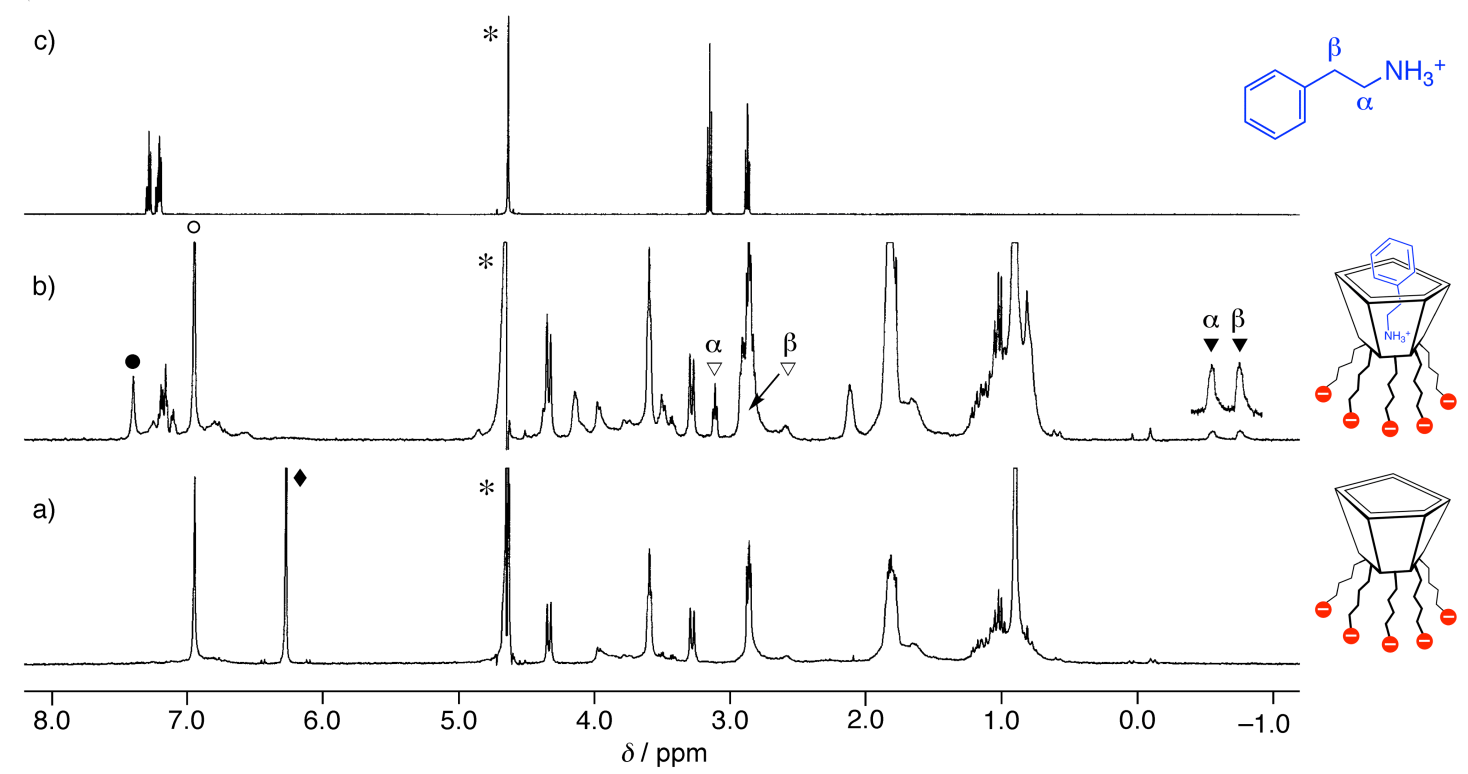

Figure S1. ${ }^{1} \mathrm{H}$ NMR spectra $\left(500 \mathrm{MHz}, \mathrm{D}_{2} \mathrm{O}, 298 \mathrm{~K}\right.$ ) of: a) $[1]=0.22 \mathrm{mM}$ (effective concentration of the monomeric species), b) $[1]=[\mathrm{Pea} \cdot \mathrm{HCl}]=0.20 \mathrm{mM}$ and c) $[\mathrm{Pea} \cdot \mathrm{HCl}]=0.20 \mathrm{mM}$. In trace (b), the following symbols designate peaks belonging to: free host $(\bigcirc)$, free guest $(\nabla)$ and endo-cavity complexed host and guest species ( and $\boldsymbol{\nabla}$, respectively). In trace (a) the peak designated with a diamond ( $)$ refers to maleic acid, added as an internal standard in a coaxial NMR tube. The residual HDO signal is marked with an asterisk.

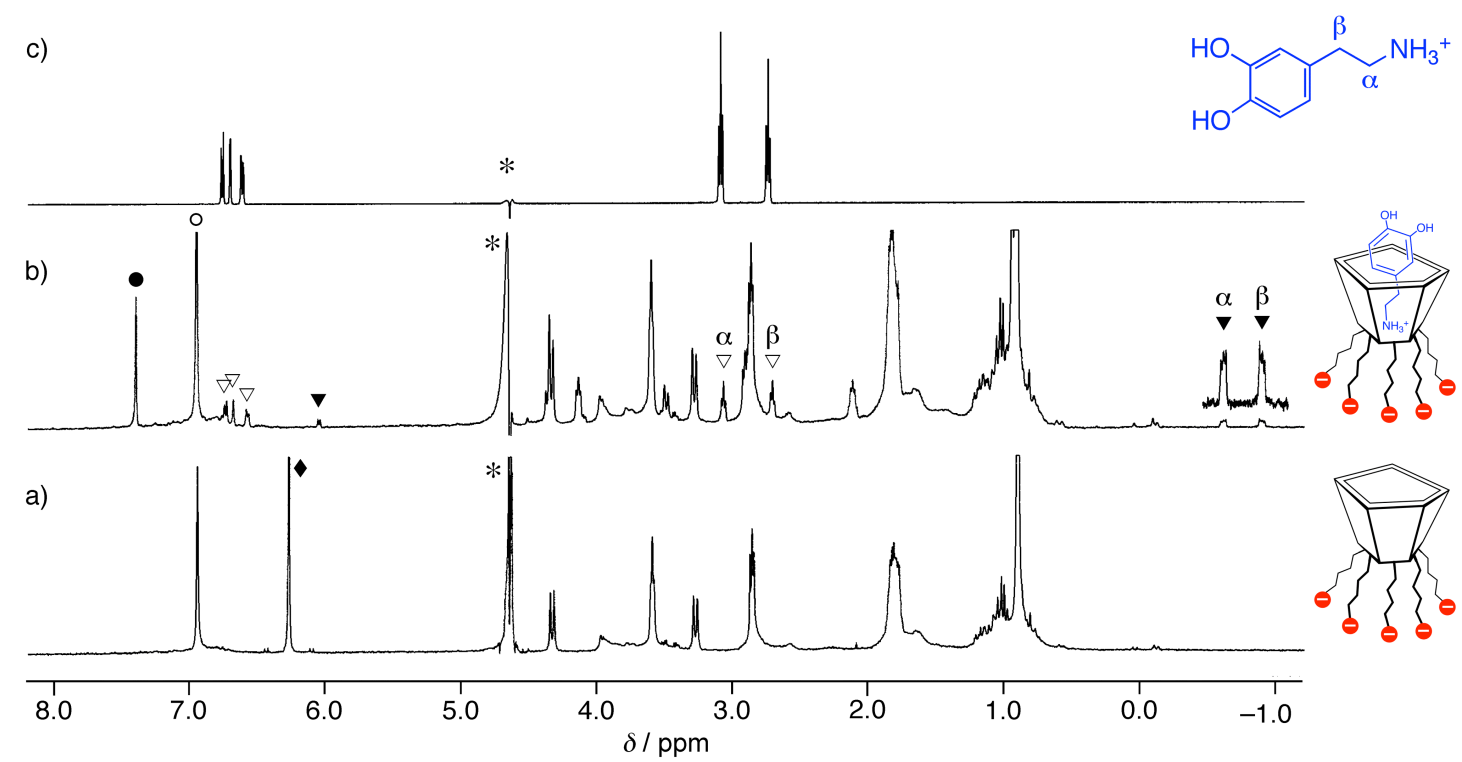

Figure S2. ${ }^{1} \mathrm{H}$ NMR spectra (500 MHz, $\mathrm{D}_{2} \mathrm{O}, 298 \mathrm{~K}$ ) of: a) $[1]=0.22 \mathrm{mM}$ (effective concentration of the monomeric species), b) $[\mathbf{1}]=[$ Dopa $\cdot \mathrm{HCl}]=0.20 \mathrm{mM}$ and c) $[$ Dopa $\cdot \mathrm{HCl}]=0.20 \mathrm{mM}$. In trace $(\mathrm{b})$, the following symbols designate peaks belonging to: free host $(\bigcirc)$, free guest $(\nabla)$ and endo-cavity complexed host and guest species ( $\bullet$ and $\boldsymbol{\nabla}$, respectively). In trace (a) the peak designated with a diamond ( ) refers to maleic acid, added as an internal standard in a coaxial NMR tube. The residual HDO signal is marked with an asterisk. 

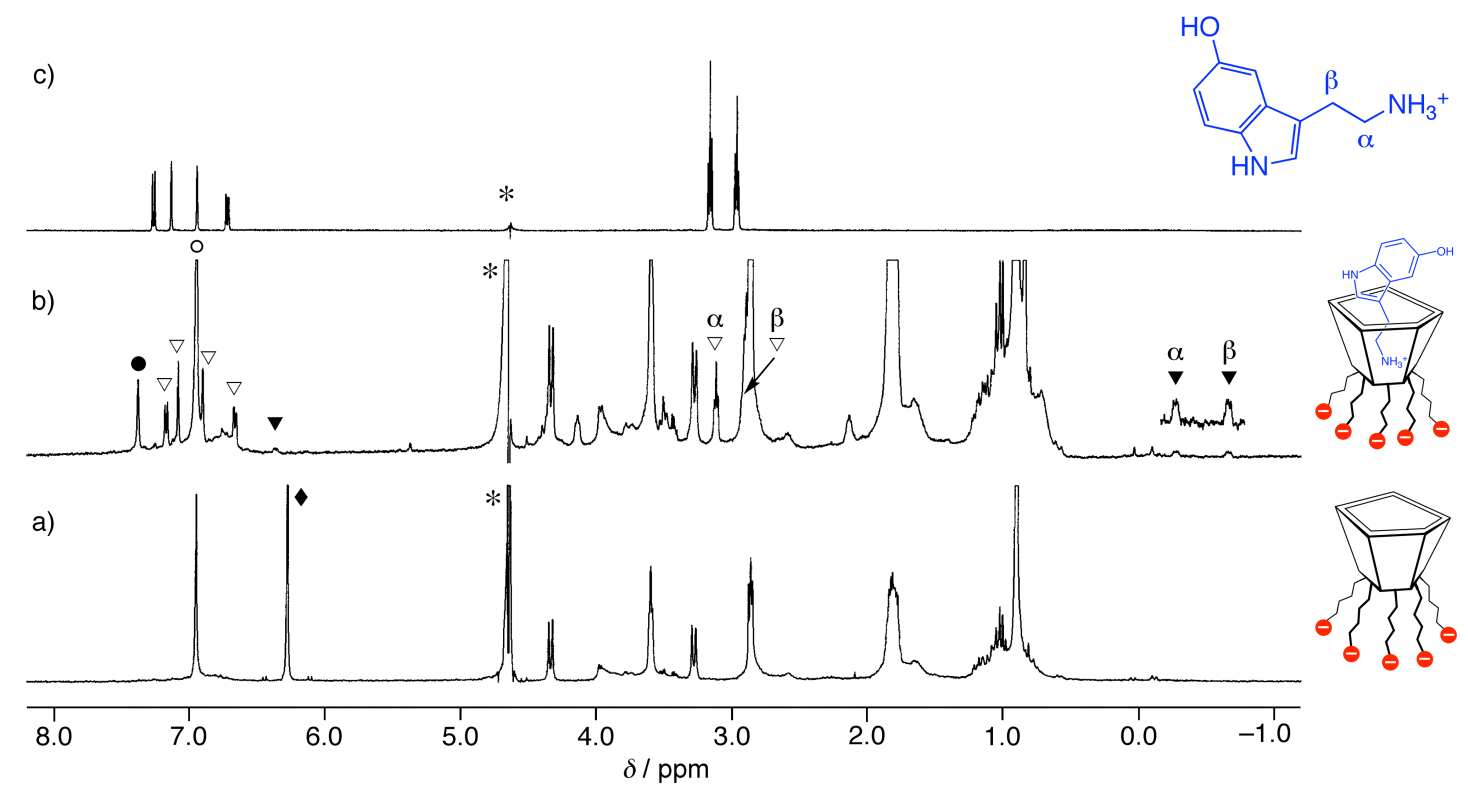

Figure S3. ${ }^{1} \mathrm{H}$ NMR spectra (500 MHz, $\mathrm{D}_{2} \mathrm{O}, 298 \mathrm{~K}$ ) of: a) $[1]=0.22 \mathrm{mM}$ (effective concentration of the monomeric species), b) $[1]=[$ Dopa $\cdot \mathrm{HCl}]=0.20 \mathrm{mM}$ and c) $[$ Dopa $\cdot \mathrm{HCl}]=0.20 \mathrm{mM}$. In trace $(\mathrm{b})$, the following symbols designate peaks belonging to: free host $(\bigcirc)$, free guest $(\nabla)$ and endo-cavity complexed host and guest species ( and $\boldsymbol{\nabla}$, respectively). In trace (a) the peak designated with a diamond ( ) refers to maleic acid, added as an internal standard in a coaxial NMR tube. The residual HDO signal is marked with an asterisk.

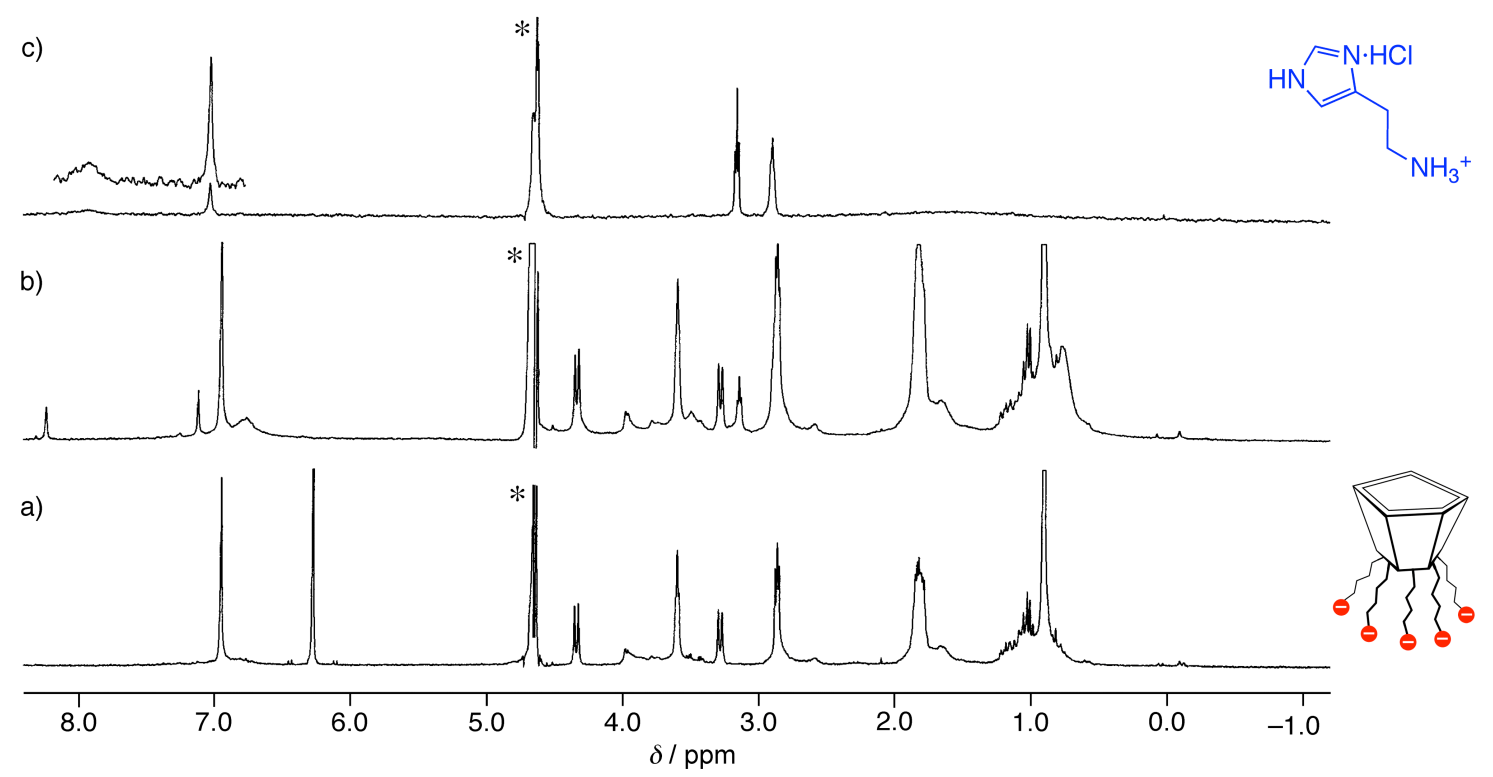

Figure S4. ${ }^{1} \mathrm{H}$ NMR spectra $\left(500 \mathrm{MHz}, \mathrm{D}_{2} \mathrm{O}, 298 \mathrm{~K}\right)$ of: a) $[\mathbf{1}]=0.22 \mathrm{mM}$, b) $[\mathbf{1}]=[\mathrm{Hist} \cdot 2 \mathrm{HCl}]=0.20 \mathrm{mM}$ and c) $[\mathrm{Hist} \cdot 2 \mathrm{HCl}]=0.20 \mathrm{mM}$. The residual $\mathrm{HDO}$ signal is marked with an asterisk. 


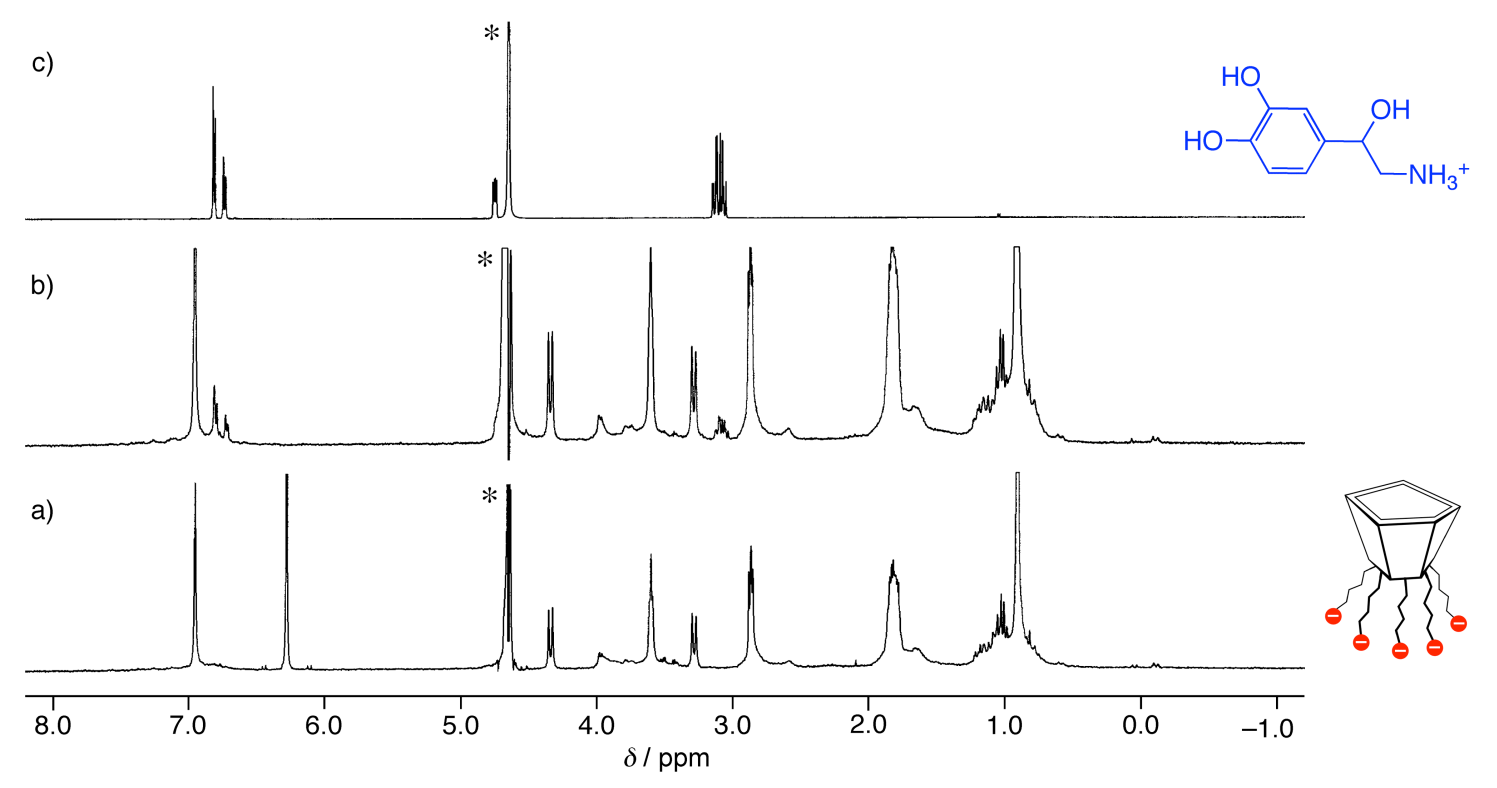

Figure S5. ${ }^{1} \mathrm{H}$ NMR spectra $\left(500 \mathrm{MHz}, \mathrm{D}_{2} \mathrm{O}, 298 \mathrm{~K}\right)$ of: a) $\left.[\mathbf{1}]=0.22 \mathrm{mM}, \mathrm{b}\right)[\mathbf{1}]=[$ Nore $\cdot \mathrm{HCl}]=0.20 \mathrm{mM}$ and c) $[\mathrm{Nore} \cdot \mathrm{HCl}]=0.20 \mathrm{mM}$. The residual $\mathrm{HDO}$ signal is marked with an asterisk.

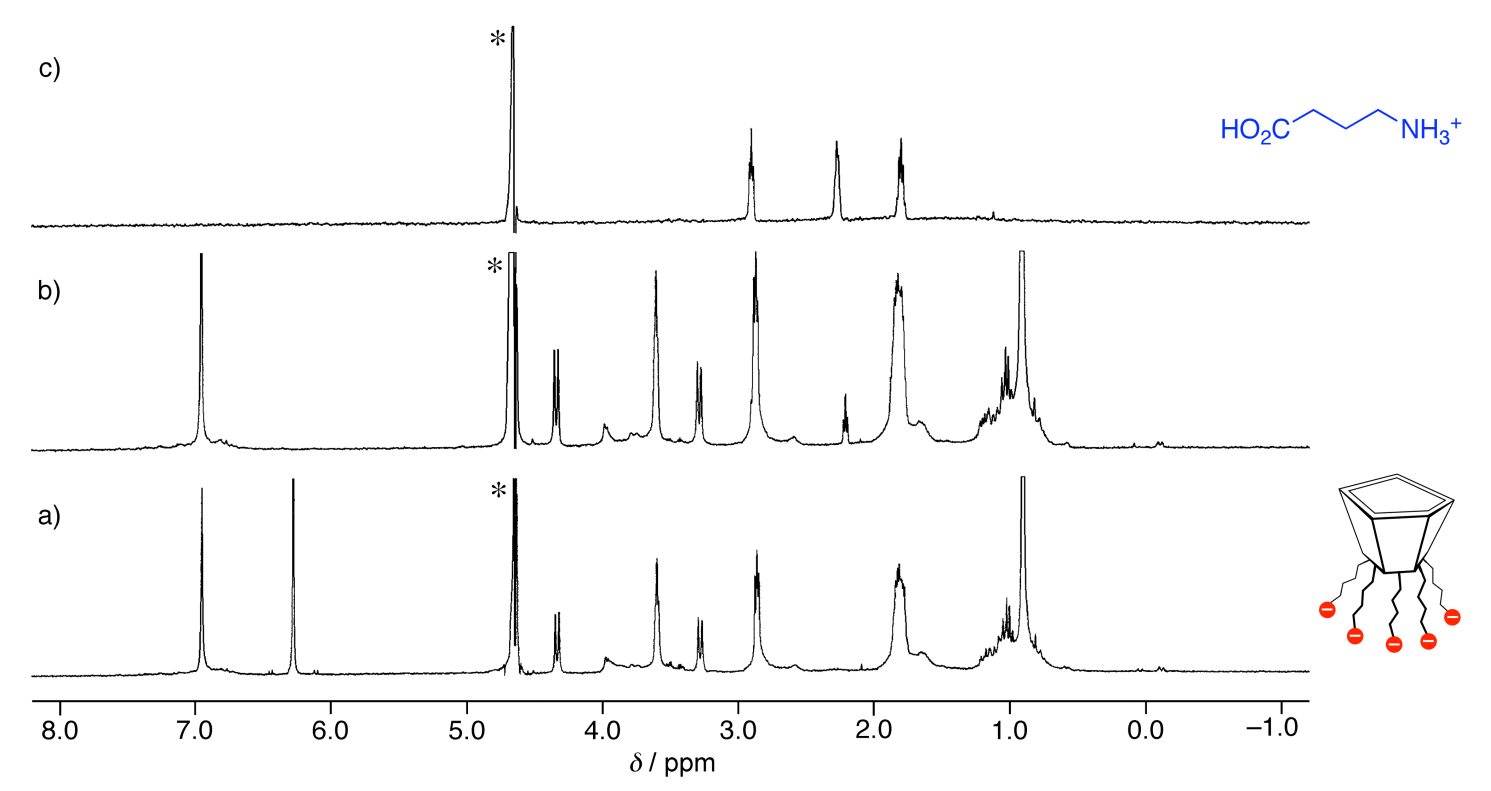

Figure S6. ${ }^{1} \mathrm{H}$ NMR spectra $\left(500 \mathrm{MHz}, \mathrm{D}_{2} \mathrm{O}, 298 \mathrm{~K}\right)$ of: a) $\left.[\mathbf{1}]=0.22 \mathrm{mM}, \mathrm{b}\right)[\mathbf{1}]=[\mathrm{Gaba} \cdot \mathrm{HCl}]=0.20 \mathrm{mM}$ and c) $[\mathrm{Gaba} \cdot \mathrm{HCl}]=0.20 \mathrm{mM}$. The residual HDO signal is marked with an asterisk. 